\title{
DIFFERENCES IN OCCUPATION OF LYING STALLS BY COWS: CASE STUDY OF PENS WITH ONE ROW OF STALLS
}

\author{
Marek Gaworski \\ Warsaw University of Life Sciences, Poland \\ marek_gaworski@sggw.pl
}

\begin{abstract}
Designs of barns with a free-stall housing system take into account various configurations of lying stalls. The distribution of the lying stalls in the pen, especially in connection with the access to the feed alley, translates into the distances covered by the cows every day. The aim of the study was to compare the lying stalls in terms of the time they were occupied by cows in a lying and standing position. The experiment concerning the occupation of lying stalls was carried out on the basis of two pens. In each pen, six cows had access to six stalls in one row. The location of the stalls in the row differed from the feed alley. The cows' activities in the stalls, i.e. lying, standing on two and four hooves, were recorded for 14 days. The average time of stall occupation for lying was $11.79 \mathrm{~h} \cdot \mathrm{day}^{-1} \cdot \mathrm{stall}^{-1}$. The research did not show any statistically significant differences between the time of occupying particular stalls in a row. Nevertheless, the research showed a tendency that the increasing distance of lying stalls from the feed alley was accompanied by a decrease in the time they were occupied by cows lying and standing on two hooves. Taking into account the relationship between the location of the stalls and the time of their occupation, the value of the Pearson linear correlation coefficient in the case of lying down time was $r=-0.9849$, and in the case of standing on two hooves $r=-0.9079$. The differentiation between the lying stalls in terms of their occupation time confirmed that cows in $\mathrm{t}$
\end{abstract}

heir activity in the pen may be guided by the distance of the lying places from the feed alley. However, further research is required to confirm the preferences for lying stalls in a pen with cows.

Keywords: barn, cow, design, lying stall, preferences.

\section{Introduction}

In dairy production systems, particular care is taken to provide the cows with the best possible living conditions. The key solutions that facilitate the achievement of such conditions include the free-stall housing system. A characteristic feature of the free-stall housing system is the ability to create a high level of cow comfort. Cow comfort in the barn with free-stall system can be considered in many areas of daily activities including lying, feeding, watering and walking in the pen with free-stalls. Dairy cows spend most of their time lying down (8-14 hours a day), so lying time can be considered as a key factor in dairy free-stall housing assessment. If stalls are uncomfortable, cows use them less time for lying, and instead they spend more time standing outside the stalls [1].

The lying time, as well as lying behaviour of cows kept in free-stall housing system, depend on many factors. Assessment of technical equipment for lying cows in a free-stall barn takes into account elements, such as individual and group characteristics of the animals, environment, especially thermal conditions [2] and temperature of the stall surface [3], as well as the design of the stalls [4], their dimensions [5] and compliance with recommendations [6;7], accessible space and type of surface/bedding material [8] intended for lying.

Including the results of the experiment carried out by [9], it is possible to show the effect of freestall sizes on some preferences and free-stall usage by dairy cows. It was indicated that providing cows with wider free-stalls can increase the lying time, because animals had less contact with the partitions dividing the lying area in the larger stalls. It was noted that a short distance between stall partitions translates to a lower risk of cows soiling the free-stall. Differences between flexible and fixed partitions in free-stalls and their effect on cow lying behaviour and preferences were investigated by [10]. Drissler et al. [11] investigated changes in lying behaviour of cows with access to different level of sand (as bedding material) in free-stalls and found reduced lying time associated with decreasing bedding. Ceballos et al. [12] showed some advantages arising from investigations aimed to improve the stall design, when using 3-D kinematics to analyse the space necessary for dairy cows when they are lying down. Considering other elements of the free-stall construction, [13] indicated that brisket-boards can be a source of decreased free-stall use by cows. Position of the neck-rail in a free-stall can decide about standing behaviour and stall cleanliness [14]. There is an indicated effect of the neck-rail position on free-stall preference, use, and cleanliness [15]. Cows may be exposed to discomfort associated with 
losses of bedding material during the period they are kept in the barn [16]. Detailed research studies taking into account the lying activity of cows are very accurately summarized in the statement that the lying time of cows reflects the welfare of dairy cows [17].

In the examples of the presented research, the topic of the relationship between the time of lying and the behaviour of cows and the factors directly identified at the lying stall is visible. Meanwhile, the characteristics of the stalls can also be looked at in terms of their location in the barn with the free-stall system. In a study by [18] the stalls located close to the feed alley were occupied for a longer time, when compared to the stalls further away from the feeding alley showing the effect of stall location on cow preferences. The results of other studies [19] showed that the stalls in the row closest to the feed alley were occupied by cows $68 \%$ of the day, while the stalls in the rows away from the feed alley were occupied by cows $48 \%$ of the day. In the same study it was also observed that the periphery stalls in each row were occupied on average $25 \%$ less time compared to centrally located stalls in the rows. The quoted research results indicate the reactions of cows to the location of the rows with lying stalls in relation to the feed alley, as well as the reaction of animals to the location of the stalls in individual rows in the pen. This behaviour of cows may be important in the assessment of different row configurations in the pen, for example, at the design stage of barns, including the use of algorithms supporting farmers and dairy cattle housing designers $[20 ; 21])$. In a study conducted on modernized dairy farms in Wisconsin, farmers indicated different preferences related to the number of rows ( 2 to 6 rows) with lying stalls in built barns [22]. Different row layouts with lying stalls in the pen, as well as a different number of stalls in a row, may be an inspiration for research on how cows react to such solutions.

The aim of the study was to compare the lying stalls in terms of the time they were occupied by cows in a lying and standing position. The factor that differentiated the lying stalls included in the experiment was their location (distance) in relation to the feed alley. The idea behind the research was to obtain information on the differences in the preference for lying stalls, which may be a valuable contribution to the design of a dairy cattle barn.

\section{Materials and methods}

The experiment was conducted in the Dairy Education and Research Centre in Agassiz (British Columbia, Canada), an experimental farm of the University of British Columbia. The daily average outside air temperature during the experiment (in November and December) varied between 4 and $8{ }^{\circ} \mathrm{C}$. The animals were cared for according to the guidelines of the Canadian Council of Animal Care [23].

Group of 12 Holstein dry (non-lactating) cows were taken to the study; from the pool of dry cows available there were selected those that showed no signs of clinical lameness and furthest from their expected calving. Cows averaged (mean \pm SD) 3.04 \pm 1.25 lactations. Average body weight of the animals was $658 \pm 63 \mathrm{~kg}$. No cows showed signs of illness during the experiment.

Cows were housed in two pens, including 6 cows per each pen. The experiment was conducted in the free-stall barn, naturally ventilated and equipped with curtained sidewalls. Each of the experimental pens included twelve free stalls, configured in two rows facing in opposite directions (see Figure 1) and had the same measurements of $10.2 \times 13 \mathrm{~m}$. The pens were equipped with lying stalls divided by partitions type Y2K-style (Artex, Langley, BC, Canada). Average width of the stalls was on average $1.17 \mathrm{~m}$. Distance (diagonally) between the neck-rail and the inner part of the rear curb was on average $2.03 \mathrm{~m}$ for stalls with open access to lay down. The lying stalls in each row were located between the pen fence and a passing area connecting the scraper alleys.

Cows in one pen had access to 6 individual feed bins (Insentec, Marknesse, the Netherlands) in the feeding zone. Water was available ad libitum from one (per pen) self-filling water bin (Insentec, Marknesse, the Netherlands). The water bin was located in the area of the feeding alley. Including needs of hygiene, the water bins were cleaned once per week. Cows were fed ad libitum a total mixed ration (TMR). The TMR content was as following: $30.54 \%$ corn silage, $46.52 \%$ alfalfa hay, $13.71 \%$ concentrate mix, and $9.23 \%$ rye grass seed straw. Fresh feed was delivered to the feed bins twice daily, i.e. at 8.00 am and $5.00 \mathrm{pm}$.

In each pen, six cows were allowed access to six lying stalls in the row near the walking alley (Fig. 1), with the second row blocked (with a chain), resulting in a 1:1 cow to stall ratio. For the purposes of 
the experiment, lying stalls in both pens were numbered including the rule presented in Fig. 1. The numbering began with the lying stall located close to the passage to the pen zone with the feed alley.

Lying stalls were fitted with a mattress (Pasture Mat, Promat Inc., Woodstock, Ontario, Canada) covered with approximately $10 \mathrm{~cm}$ of washed river sand. Before the experiment, sand on the lying stalls was filled using a tractor with a sand spreader and raked for an even surface between the rear curb and the brisket board. Twice during the day, when most of the cows were standing by the feed alley (during feeding), faeces were removed from the stalls, bedding material levelled using rakes. The scraper alleys, covered with a textured rubber surface, were cleaned (scraped) automatically 6 times per day. However, crossover alleys were grooved concrete and manually cleaned twice a day.

Before the experiment, cows were housed for one week in the same type (like experimental) pen with $12(2 \times 6)$ stalls and all opened lying stalls. In the experimental pens each group was allowed to stabilize for $3 \mathrm{~d}$ and then baseline recordings for lying behaviors were taken for 14 consecutive days. In the middle of this period, i.e. after 7 days, two groups of cows were swapped between the pens.

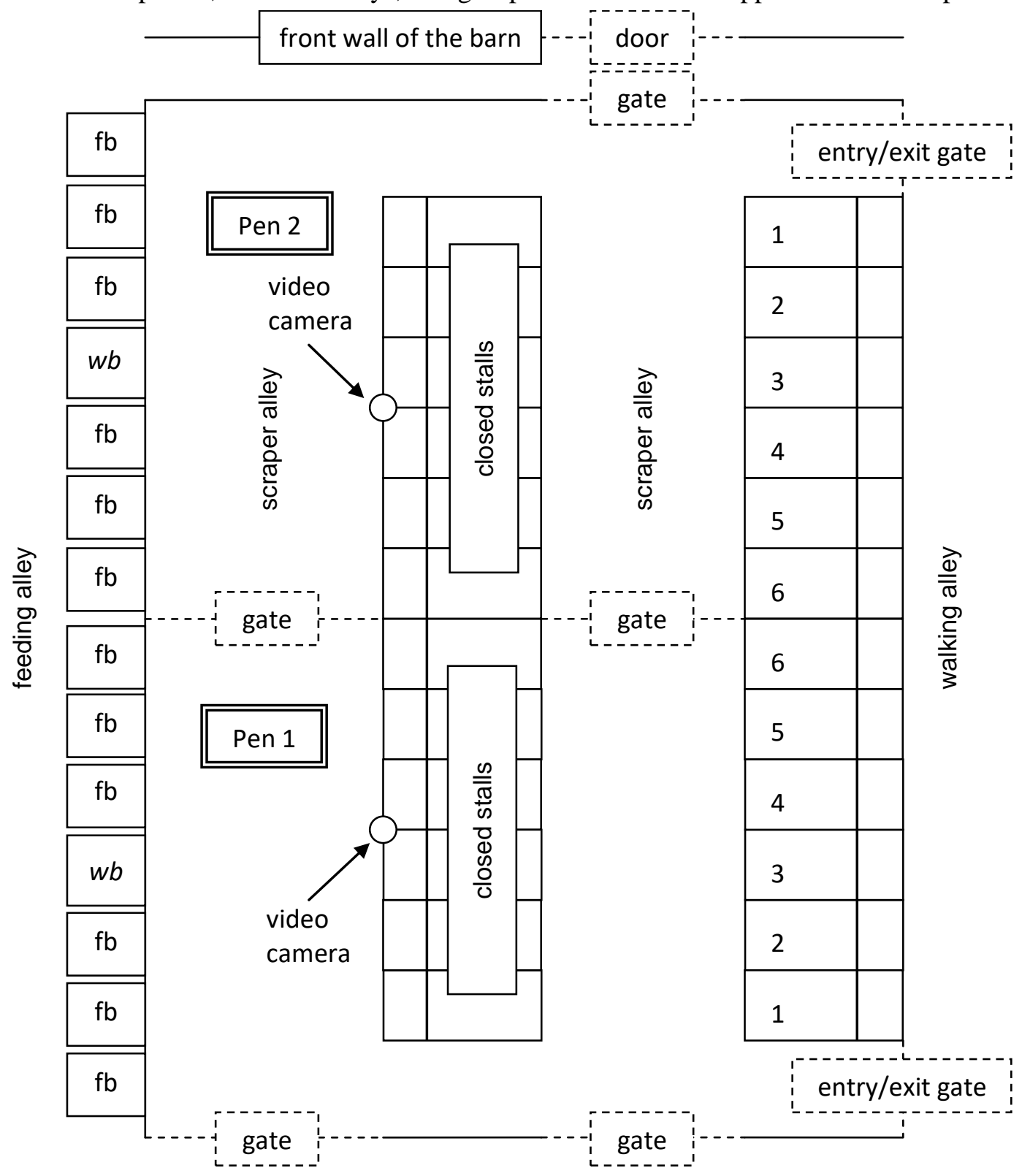

neighbouring pen

Fig. 1. Scheme of pens used for the experiment with closed stalls:

$\mathrm{fb}$ - feed bin, $w b$ - water bin 
To record the cows, the video camera (WV-BP330, Panasonic, Osaka, Japan) was positioned $8 \mathrm{~m}$ above the pen. The camera was attached to a digital video recording system (Genetec Inc., Saint-Laurent, QC, Canada). A red light bulb $(100 \mathrm{~W})$ was placed $8 \mathrm{~m}$ above the pen in order to facilitate video recording at night.

Behaviour of the cows within the experiment was video-recorded for 7 days per week including 24 hours of recording per day. Video recordings were scan sampled at 10 min intervals to identify the stall use and cow positions. The following positions of cows in the stall were included: lying, standing with two hooves in the stall and standing with four hooves in the stall. Data were collected to calculate the total time of occupation per stall (considered as the experimental unit) for each of the mentioned activities. Cows were never observed lying down outside of the lying stalls.

The lying stall was the experimental unit, so only stall-based results were statistically analyzed using Statistica v.13.1 software [24]. Cow-based results were provided only for descriptive purposes. The time of stall occupation in total, and separately by the cow position, i.e. lying, standing with two and four hooves in the stall was analyzed. ANOVA was done to test the effect of stall location on the time of occupation. Significance was declared at $\alpha=0.05$. The Pearson linear correlation coefficient was used to evaluate the trends in changes in the time taken to occupy the lying stalls.

\section{Results and discussion}

The analysis of the material recorded in two pens over a 14-day period shows that the average time of stall occupation for lying was (mean \pm SD) $707.44 \pm 71.58 \mathrm{~min} \cdot \mathrm{day}^{-1} \cdot$ stall $^{-1}$, while the average time of stall occupation by cows standing with two and four hooves in the stall was (mean \pm SD) $114.82 \pm$ $40.83 \mathrm{~min} \cdot \mathrm{day}^{-1} \cdot \mathrm{stall}^{-1}$ and $15.24 \pm 7.97 \mathrm{~min} \cdot \mathrm{day}^{-1} \cdot \mathrm{stall}^{-1}$, respectively. The activity of the cows in both experimental pens differed in terms of the time they had taken to lie down and standing (Table 1). These were not only the differences in lying and standing times between pens, but also in the structure of time spent in pens on individual activities. Comparing the results of the research, the percentage of cows' lying and standing positions in pen 1 was $81.4 \% / 18.6 \%$, and in pen $2-87.4 \% / 12.4 \%$, respectively.

Table 1

\section{Time of stall occupation in two experimental pens for three kinds of cow activities, lying, standing with two hooves and four hooves}

\begin{tabular}{|c|c|c|}
\hline \multirow{2}{*}{ Stalls occupied for: } & \multicolumn{2}{|c|}{ Time of stall occupation [min $\cdot$ day $^{\mathbf{1}} \cdot$ stall $^{\mathbf{1}}$ ] } \\
\cline { 2 - 3 } & Pen 1 & Pen 2 \\
\hline Lying & $665.95 \pm 59.95$ & $748.93 \pm 59.57$ \\
\hline Standing with two hooves & $140.36 \pm 41.70$ & $89.29 \pm 19.08$ \\
\hline Standing with four hooves & $11.67 \pm 4.46$ & $18.81 \pm 9.44$ \\
\hline
\end{tabular}

Taking into account the research objective, it was of key importance to compare the time of occupying particular lying stalls. On the basis of analogous data from two pens, the average time of lying down, standing on two hooves and four hooves on individual stalls was compiled, assuming the range from 0 to $100 \%$ on the abscissa (Fig. 2). The proposed range on the abscissa axis resulted from the applied rule that the value of 0 on the scale corresponded to the stall in the row located closest to the feed alley in the pen. On the other hand, the next values on the $\mathrm{X}$ axis (from 20 to 100\%) show the position of the next lying stalls from the 0 stall at a distance of $20 \%, 40 \%$ etc. of the total length of the row. Translating this approach to the lying stalls in the pens included in the experiment, stall 0 (on the abscissa - Fig. 2) was stall 1 in the pens (Fig. 1), i.e. located in the closest distance from the feed alley. On the other hand, for example, the stall with the value of $100 \%$ on the abscissa axis (Fig. 2) was stall 6 in the pens (Fig. 1), i.e. the farthest from the stall 0 and, at the same time, from the feed alley.

The results of the research presented in Figure 2 show that the increasing distance of the lying stalls from the feed alley is accompanied by a decrease in the time they are occupied by cows lying down and standing on two hooves. In the case of standing on four hooves, the tendency is not clear (Fig. 2). The tendencies of changes in the time of taking stalls to lying down and standing on two and four hooves was analyzed by correlation taking into account the relationship between the location of the stalls and the time of their occupation. The value of the Pearson linear correlation coefficient in the case of lying 
down time was $r=-0.9849$, in the case of standing on two hooves $r=-0.9079$ and standing on four hooves $r=-0.4251$.

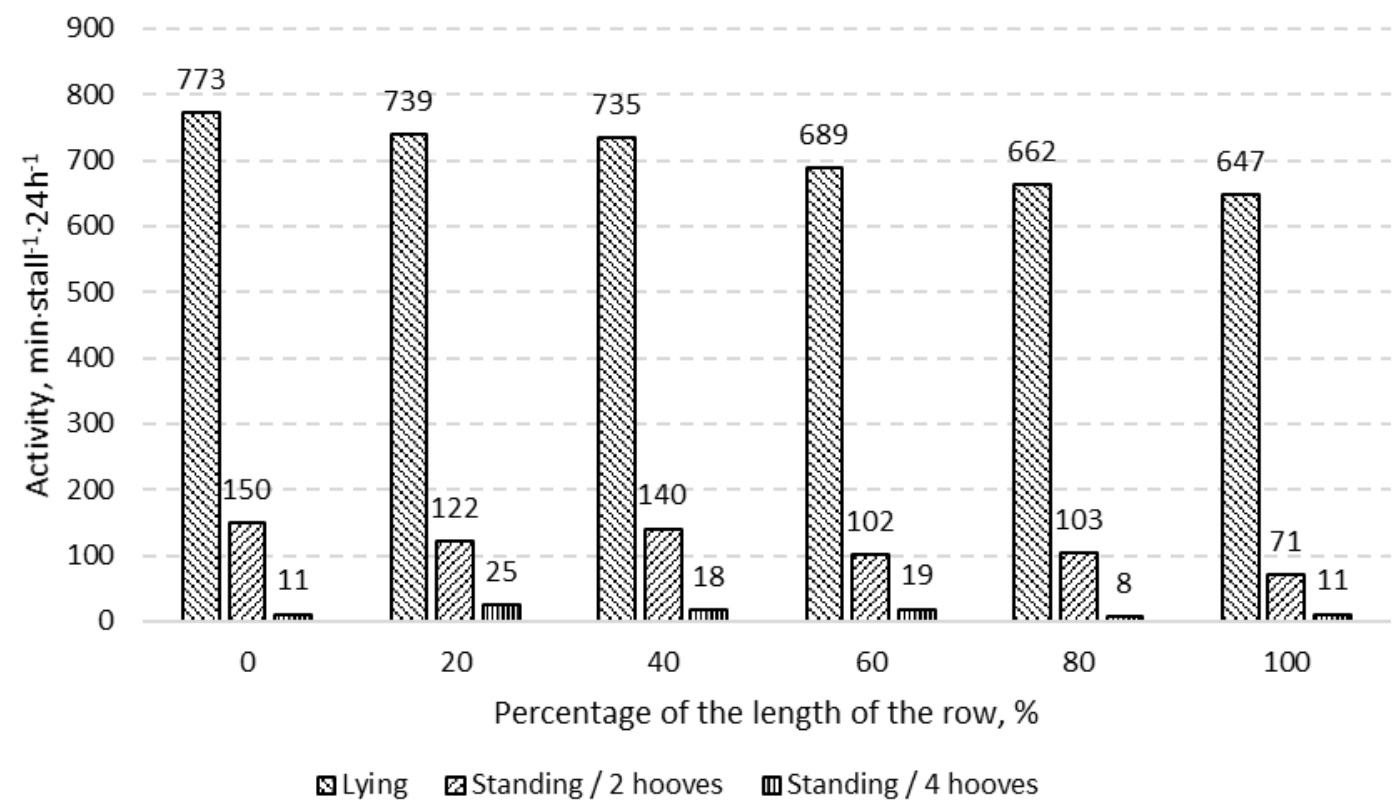

Fig. 2. Comparison of time of stall occupation by cows for lying, standing with 2 hooves and 4 hooves, taking into account the position of the stalls expressed as a percentage of their distance from the zero stall ( 0 stall - located closest to the feed alley) in the row of all stalls

The analysis of variance, based on the data from two pens, did not show any significant differences $(p>0.05)$ between the stalls in a row in the case of the time they were occupied by cows lying down, with two and four hooves in the stall. Comparing the average time of occupying the periphery stalls in a row (stalls 1 and 6 - Fig. 1) and centrally located stalls (stalls 2 to 5 - Fig. 1), no significant differences were also found $(p>0.05)$ for the case of lying and standing on two hooves and four hooves.

Considering the data collected in the study, other aspects of stall usage were observed. Including distribution of time of individual stall occupation in both pens, the average time of stall occupation was calculated for two group of stalls, i.e. 1-3 and 4-6 (Fig. 1). Stalls 1-3 as one group and stalls 4-6 as a second group differed in time of occupation by lying, standing with two hooves and four hooves. There was significant difference in time of stall occupation for lying between the group of stalls 1-3 and 4-6 $(F=12.179, p=0.007)$. The same significant difference - including the results of the ANOVA test was found for the time of stall occupation for standing of cows with two hooves in lying stalls $(F=12.792, p=0.006)$. However, comparison of the time of stall occupation for standing with four hooves did not show significant difference $(F=1.778, p=0.215)$ between the groups of stalls $1-3$ and 4-6.

Summarizing the conducted research, the time of occupying the stalls by cows lying down for two pens was on average $11.79 \mathrm{~h} \cdot \mathrm{day}^{-1} \cdot \mathrm{stall}^{-1}$. The data presented in the literature summarized by [17], but referring directly to cows, show that the lying time of cows ranges from 8 to $13 \mathrm{~h} \cdot \mathrm{d}^{-1}$, with the most frequently indicated mean between 10 and $12 \mathrm{~h} \cdot \mathrm{d}^{-1}$. The results of the experiment confirm many previous observations about cow behaviour and preferences in relation to some facilities in the free-stall housing system in a barn. In the experiment performed, a pen with access to only one row of lying stalls was included. As a result, it was possible to examine the effect of only one variable, i.e. the location (in relation to the feed alley) of the stalls in a row on the time of their occupation. As a result of the conducted experiment in pens with free-stalls designed in three rows, [19] indicated that cows preferred stalls in the row closest to the feeding alley; in this experiment, however, there were two variables, i.e. three separate rows with stalls and four stalls in each row at a different distance from the feed alley, which could determine overlapping of the effects of the location of the stalls in relation to the feed alley. Wagner-Storch et al. [25] showed that cow lying and stall occupation percentages were highest for stalls located not at the end of a section and on the outside row. The stall occupation varied by the base type for the time the cows were exposed to the stall; the inside barn temperature was also important in the 
considerations on cow behaviour. Such results indicate that stall location should be controlled for in the studies which examine the factors affecting stall use. The presented research confirms that not only some technical and functional features of lying stalls, like dimensions [9], quality of bedding material [1] and its amount [11], as well as specific equipment, i.e. brisket-board [13], partitions [10], neck-rail [14] and other technological details [26;27] decide about cow preferences and comfort when kept in the freestall housing system. The preference of dairy cows for lying stalls can also be associated with their location in the pen, which was noted in the research many years ago. The observations of Schmisseur et al. [28] showed that a significant share of cows tended to prefer individual lying stalls. In other studies [29] it was noted that the dominant cows in the herd occupied stalls close to the entrance in one of the rows. Such research information confirms the importance of the layout of stalls and rows in the pen and can be a valuable guide to use in the barn design process to improve and develop the dairy production on the farm.

\section{Conclusions}

The differentiation between the lying stalls in terms of their occupation time confirmed that cows in their activity in the pen may be guided by the distance of the lying places from the feed alley. The concept of laying stalls in the pen, taken into account at the design stage, can make an important contribution to improving the welfare of cows. Accurate recognition of the preferences for lying stalls in pens with a different number of rows, lying stalls and their location in relation to the feed alley and the drinker requires further continuation of the research.

\section{Acknowledgements}

I would like to give my thanks to the faculty and staff at the UBC Dairy Education and Research Centre in Agassiz (Canada), as well as the University's Animal Welfare Program for the help necessary to prepare and conduct the experiment.

\section{References}

[1] Fregonesi J.A., Veira D.M., von Keyserlingk M.A.G., Weary D.M. Effects of bedding quality on lying behavior of dairy cows. Journal of Dairy Science, vol. 90, 2007, pp. 5468-5472.

[2] Herbut P., Angrecka S. The effect of heat stress on time spent lying by cows in a housing system. Annals of Animal Science, vol. 18, 2018, pp. 825-833.

[3] Angrecka S., Herbut P. Impact of barn orientation on insolation and temperature of stalls surface. Annals of Animal Science, vol. 16, 2016, pp. 887-896.

[4] Abade C.C., Fregonesi J.A., von Keyserlingk M.A.G., Weary D.M. Dairy cow preference and usage of an alternative free stall design. Journal of Dairy Science, vol. 98, 2015, pp. 960-965.

[5] de Boyer des Roches A., Lardy R., Capdeville J., Mounier L., Veissier I. Do International Commission of Agricultural and Biosystems Engineering (CIGR) dimension recommendations for loose housing of cows improve animal welfare? Journal of Dairy Science, vol. 102, 2019, pp. 10235-10249.

[6] Gaworski M., Boćkowski M. Method for comparing current versus recommended housing conditions in dairy cattle production. Agricultural and Food Science, vol. 27, 2018, pp. 17-27.

[7] Lardy R., de Boyer des Roches A., Capdeville J., Bastien R., Mounier L., Veissier I. Refinement of international recommendations for cubicles, based on the identification of associations between cubicle characteristics and dairy cow welfare measures. Journal of Dairy Science, vol. 104, 2021, pp. 2164-2184.

[8] Ferraz P.F.P., Ferraz G.A.S., Leso L., Klopčič M., Barbari M., Rossi G. Properties of conventional and alternative bedding materials for dairy cattle. Journal of Dairy Science, vol. 103, 2020, pp. 8661-8674.

[9] Tucker C.B., Weary D.M., Fraser D. Free-stall dimensions: Effects on preference and stall usage. Journal of Dairy Science, vol. 87, 2004, pp. 1208-1216.

[10] Ruud L.E., Bøe K.E. Flexible and fixed partitions in freestalls-Effects on lying behavior and cow preference. Journal of Dairy Science, vol. 94, 2011, pp. 4856-4862.

[11] Drissler M., Gaworski M., Tucker C.B., Weary D.M. Freestall maintenance: Effects on lying behavior of dairy cattle. Journal of Dairy Science, vol. 88, 2005, pp. 2381-2387. 
[12] Ceballos A., Sanderson D., Rushen J. Weary D.M. Improving stall design: Use of 3-D kinematics to measure space use by dairy cows when lying down. Journal of Dairy Science, vol. 87, 2004, pp. 2042-2050.

[13] Tucker C.B., Zdanowicz M., Weary D.M. Brisket boards reduce freestall use. Journal of Dairy Science, vol. 89, 2006, pp. 2603-2607.

[14] Fregonesi J.A., von Keyserlingk M.A.G., Tucker C.B., Veira D.M., Weary D.M. Neck-rail position in the free stall affects standing behavior and udder and stall cleanliness. Journal of Dairy Science, vol. 92, 2009, pp. 1979-1985.

[15] Tucker C.B., Weary D.M., Fraser D. Influence of neck-rail placement on free-stall preference, use, and cleanliness. Journal of Dairy Science, vol. 88, 2005, pp. 2730-2737.

[16] Rocha Á.G.F., Gaworski M. Sand losses out the pens in barn with free-stall housing system. Agronomy Research, vol. 15, 2017, pp. 530-539.

[17] Tucker C.B., Jensen M.B., de Passillé A.M., Hänninen L., Rushen J. Invited review: Lying time and the welfare of dairy cows. Journal of Dairy Science, vol. 104, 2021, 20-46.

[18] Gaworski M. Free-stall use and preferences in dairy cows: A case study on neck rails covered by foam. Animals, vol. 9, 772, 2019, p. 1-11.

[19] Gaworski M.A., Tucker C.B., Weary D.M., Swift M.L. Effects of stall design on dairy cattle behaviour. Fifth International Dairy Housing Conference, January 29-31, 2003, St. Joseph, MI, Fort Worth, TX, USA, pp. 139-146.

[20] Fernández M.E., Mariño R.A., Carreira X.C. Algorithms for dairy barn design: Resting, feeding, and exercise. Journal of Dairy Science, vol. 89, 2006, pp. 2784-2798.

[21] Leso L., Conti L., Rossi G., Barbari M. Criteria of design for deconstruction applied to dairy cows housing: a case study in Italy. Agronomy Research, vol. 16, 2018, pp. 794-805.

[22] Bewley J., Palmer R.W., Jackson-Smith D.B. A comparison of free-stall barns used by modernized Wisconsin dairies. Journal of Dairy Science, vol. 84, 2001, pp. 528-541.

[23] Canadian Council of Animal Care. Guide to the Care and Use of Experimental Animals; Olfert, E.D., Cross, B.M., McWilliam, A.A., Eds.; CCAC: Ottawa, ON, Canada, 1993, vol. 1.

[24] Statistica v.13.1. StatSoft, Cracow, Poland.

[25] Wagner-Storch A.M., Palmer R.W., Kammel D.W. Factors affecting stall use for different freestall bases. Journal of Dairy Science, vol. 86, 2003, pp. 2253-2266.

[26] Kic P. Influence of housing technology on dust level in cowsheds. International conference "Engineering for Rural Development", May 23-25, 2018, Jelgava, Latvia, pp. 24-27.

[27] Nipers A., Pilvere I., Valdovska A., Proskina L. Assessment of key aspects of technologies and cow farming for milk production in Latvia. International conference "Engineering for Rural Development”, May 25-27, 2016, Jelgava, Latvia, pp. 175-181.

[28] Schmisseur W.E., Albright J.L., Dillon W.M., Kehrberg E.W., Morris W.H.M. Animal behavior responses to loose and free stall housing. Journal of Dairy Science, vol. 49, 1966, pp. 102-104.

[29] Friend T.H., Polan C.E. Social rank, feeding behavior, and free stall utilization by dairy cattle. Journal of Dairy Science, vol. 57, 1974, pp. 1214-1220. 